\title{
Recent progress in pancreatic islet cell therapy
}

\author{
Erinn Zixuan Sim, Nobuaki Shiraki and Shoen Kume*
}

\begin{abstract}
Human pluripotent stem cells (PSCs), including human embryonic stem cells and induced pluripotent stem cells, are promising cell sources in regenerating pancreatic islets through in vitro directed differentiation. Recent progress in this research field has made it possible to generate glucose-responsive pancreatic islet cells from PSCs. Single-cell RNA sequencing techniques have been applied to analyze PSC-derived endocrine beta-cells, which are then compared with human islets. This has led to the identification of novel signaling pathways and molecules involved in lineage commitment during pancreatic differentiation and maturation processes. Single-cell transcriptomics are also used to construct a detailed map of in vivo endocrine differentiation of developing mouse embryos to study pancreatic islet development. Mimicking those occurring in vivo, it was reported that differentiating PSCs can generate similar islet cell structures, while metabolomics analysis highlighted key components involved in PSCderived pancreatic islet cell function, providing information for the improvement of in vitro pancreatic maturation procedures. In addition, cell transplantation into diabetic animal models, together with the cell delivery system, is studied to ensure the therapeutic potentials of PSC-derived pancreatic islet cells. Combined with gene-editing technology, the engineered mutation-corrected PSC lines originated from diabetes patients could be differentiated into functional pancreatic islet cells, suggesting possible autologous cell therapy in the future. These PSC-derived pancreatic islet cells are a potential tool for studies of disease modeling and drug testing. Herein, we outlined the directed differentiation procedures of PSC-derived pancreatic islet cells, novel findings through transcriptome and metabolome studies, and recent progress in disease modeling.
\end{abstract}

Keywords: Pluripotent stem cells, Directed differentiation, Pancreatic islets, Transplantation, Disease modeling

\section{Background}

Pancreatic islet cell therapy is a promising treatment for diabetes mellitus; however, it is hampered by the persistent shortage of donor islets [1]. Human pluripotent stem cells (PSCs), which possess the ability of indefinite proliferation and differentiation capacity into all cell types, are a potential source in generating pancreatic islets for replacement therapy. Upon enormous progress in this research field made in the past decade, directed differentiation of insulin-producing pancreatic islet cells using human embryonic stem cells [2] and induced pluripotent stem cells [3], has become feasible. Phase I/II clinical

\footnotetext{
* Correspondence: skume@bio.titech.ac.jp

School of Life Science and Technology, Tokyo Institute of Technology,

4259-B-25 Nagatsuta-cho, Midori-ku, Yokohama, Kanagawa 226-8501, Japan
}

trials were launched in 2014 and 2017 using hESCderived pancreatic progenitors (NCT02239354, NCT03163511). In this review, we discuss the progress of in vitro pancreatic differentiation procedures, the analysis of the PSC-derived pancreatic islet cellular identity, cell transplantation, and applications of differentiated PSCs in disease modeling.

\section{Growth factors and small molecules that facilitate in vitro pancreatic differentiation}

Islets of Langerhans, commonly referred to as pancreatic islets, are derived from the definitive endoderm. The endoderm then folds to form the primitive gut tube, followed by region specification and organ-specific bud formation, subsequently giving rise to various respiratory, digestive organs, including the dorsal and ventral

(c) The Author(s). 2021 Open Access This article is licensed under a Creative Commons Attribution 4.0 International License, which permits use, sharing, adaptation, distribution and reproduction in any medium or format, as long as you give appropriate credit to the original author(s) and the source, provide a link to the Creative Commons licence, and indicate if changes were made. The images or other third party material in this article are included in the article's Creative Commons licence, unless indicated otherwise in a credit line to the material. If material is not included in the article's Creative Commons licence and your intended use is not permitted by statutory regulation or exceeds the permitted use, you will need to obtain permission directly from the copyright holder. To view a copy of this licence, visit http://creativecommons.org/licenses/by/4.0/. 
pancreas. Pancreatic buds, where the pancreatic progenitors originate, are marked by pancreatic and duodenal homeobox 1 (PDX1), a gene required for pancreatic growth. Developmental processes continue with an expansion of these pancreatic progenitors followed by fate divergence into exocrine and endocrine progenitors. The morphogenetic processes and expression profiles of key lineage-specific genes that contributed to pancreatic development in vertebrates were studied, and this knowledge was applied to in vitro directed differentiation of pancreatic islet cells from PSCs [4-6].

Stepwise pancreatic differentiation protocols from PSCs are established by mimicking the in vivo pancreatic development processes. PSCs are sequentially differentiated into definitive endoderm (DE), primitive gut tube (PG), pancreatic progenitor (PP), endocrine progenitor (EP), then into hormone-expressing endocrine cells (EC). The in vitro differentiation procedures utilize the inhibition or activation of WNT, transforming growth factor- $\beta$ (TGF- $\beta$ ) superfamily signaling pathways, such as Activin, Nodal, and Bone Morphogenic Protein (BMP), retinoic acid (RA), and protein kinase C (PKC) signaling (Fig. 1a). Combined treatment of the above growth factors and small molecules were adopted for the directed differentiation of pancreatic endocrine beta cells (Table 1).
DE differentiation from PSCs involves the activation of Activin/Nodal and WNT signaling. Inactivation of Wnt3 during mice embryogenesis resulted in defective primitive streak formation [11]. The endoderm failed to form in the Nodal-Smad2 mutant mice [7]. This knowledge was applied for DE induction from PSCs. Activin is used since it binds to and activates the endogenous Nodal receptor [8]. D'Amour et al. successfully directed PSCs into DE cells under low serum and high Activin A concentration [9]. They later improved the DE differentiation efficacy by adding a WNT protein, Wnt3a, on the first day of Activin A treatment [12]. In consideration of differentiation efficiency, stability, and cost, Kunisada et al. substituted Wnt3a with CHIR99021, a highly selective glycogen synthase kinase 3 beta (GSK3 $\beta$ ) inhibitor. Treatment of CHIR99021, together with Activin A, induced a higher percentage of DE cells compared to Wnt3a and Activin A [13].

PG formed after the establishment of DE, coincident with a transition from a two-dimensional cell sheet into a three-dimensional tube-like structure [6]. Fibroblast growth factors (FGFs) and sonic hedgehog ( $\mathrm{SHH}$ ) signaling pathways take part in this event. In chick embryos, Shh is expressed along the gut tube but is absent in the pancreatic endoderm. The removal of notochord results in an induction of Shh expression in the pancreas and a

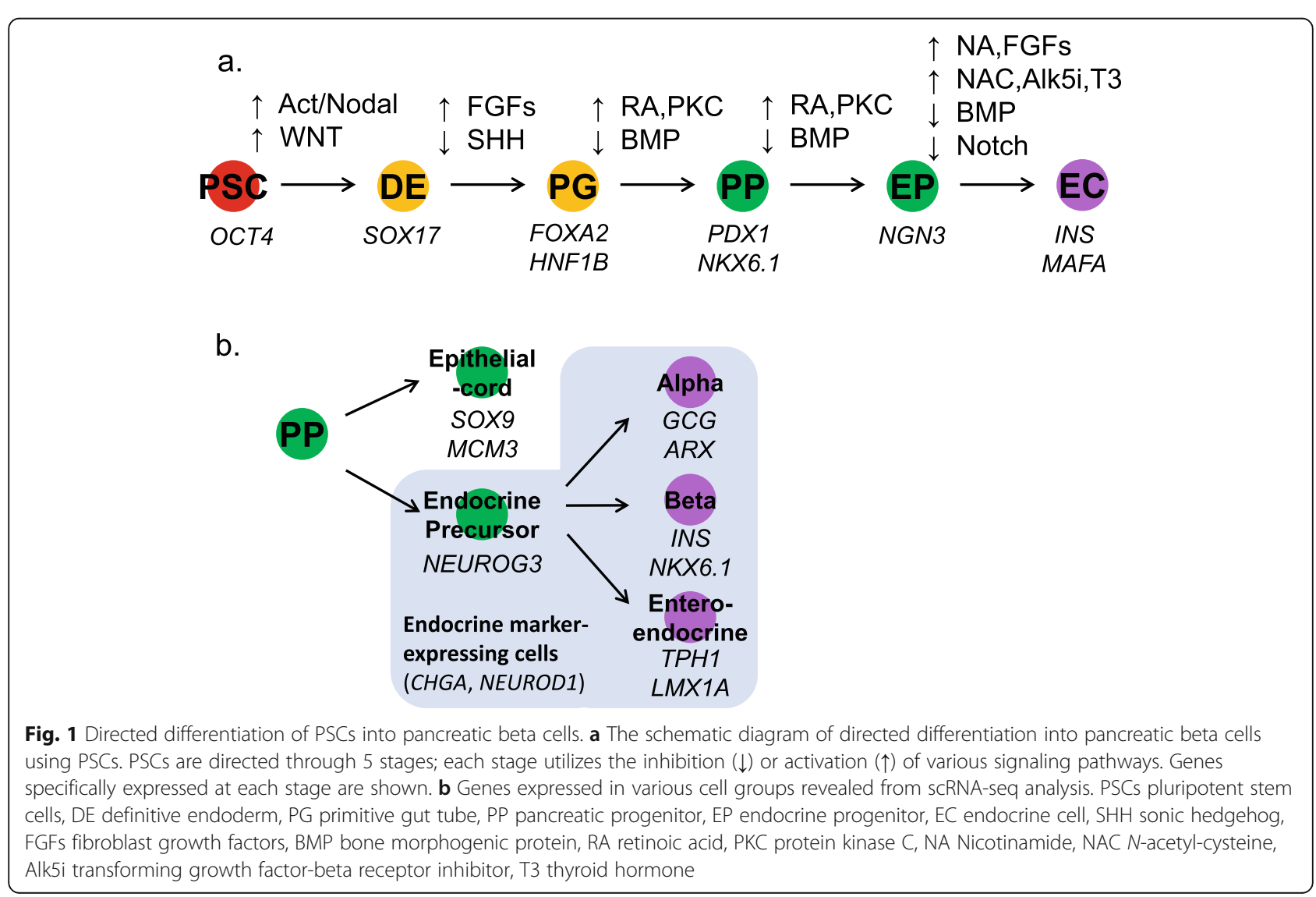


Table 1 A list of growth factors and small molecules adopted in the in vitro differentiation procedures

\begin{tabular}{|c|c|c|c|c|c|}
\hline \multirow[t]{2}{*}{ Stages } & \multirow{2}{*}{$\begin{array}{l}\text { Growth factors/ } \\
\text { small molecules }\end{array}$} & \multirow[t]{2}{*}{ Signaling pathways } & \multirow[t]{2}{*}{ Functions } & \multicolumn{2}{|c|}{ References } \\
\hline & & & & $\begin{array}{l}\text { Rodent } \\
\text { in vivo }\end{array}$ & $\begin{array}{l}\text { Human } \\
\text { in vitro }\end{array}$ \\
\hline \multirow[t]{3}{*}{ DE } & Activin A & $\begin{array}{l}\text { TGF- } \beta \text { superfamily } \\
\text { member }\end{array}$ & Induce DE differentiation & {$[7,8]$} & {$[9,10]$} \\
\hline & Wnt3a & TGF- $\beta$ superfamily & Induce mesendoderm differentiation & [11] & [12] \\
\hline & CHIR99021 & GSK3 $\beta$ inhibitor (WNT) & Promote SOX17 expression better than Wnt3a & - & [13] \\
\hline \multirow[t]{3}{*}{ PG } & FGF10 & FGF signaling & Induce PG differentiation & {$[14,15]$} & [12] \\
\hline & KAAD-cyclopamine & SHH inhibitor & Enhance DE differentiation & {$[6,16]$} & [12] \\
\hline & KGF, FGF7 & FGF signaling & $\begin{array}{l}\text { Enhance PG and differentiation to the pancreatic } \\
\text { lineage }\end{array}$ & {$[4,17]$} & [18-20] \\
\hline \multirow[t]{6}{*}{ PP, EP } & RA & RA signaling & Promote PDX1 expression & {$[4-6]$} & [10] \\
\hline & SANT1 & SHH inhibitor & Enhance DE differentiation & {$[6,16]$} & [18] \\
\hline & Noggin, LDN193189 & BMP inhibitors & Enhance differentiation to the pancreatic lineage & {$[4]$} & [18-22] \\
\hline & ILV, PDBu, TPB & PKC activator & Promote PDX1 or NKX6.1 expression & - & {$[18,19,23]$} \\
\hline & EGF & EGF signaling & Enhance PP proliferation & {$[4,24]$} & {$[22,25,26]$} \\
\hline & Sodium cromoglicate & BMP inhibitor & Promote NGN3 expression & - & [27] \\
\hline \multirow[t]{7}{*}{ EC } & Alk5i & TGF- $\beta$ receptor inhibitor & $\begin{array}{l}\text { Induce differentiation to the endocrine lineage from } \\
\text { PP }\end{array}$ & {$[4,6]$} & [18] \\
\hline & Nicotinamide & $\begin{array}{l}\text { Amide form of Vitamin } \\
\text { B3 }\end{array}$ & Induce EC differentiation & - & {$[10,21,22,28]$} \\
\hline & $\mathrm{N}$-acetyl cysteine & Antioxidant & Promote MAFA nuclear localization & [29] & [20] \\
\hline & T3 & Thyroid hormone & Promote co-expression of NKX6.1 and INS & {$[30]$} & {$[19,20]$} \\
\hline & $\begin{array}{l}Y \text {-secretase inhibitor } \\
X X\end{array}$ & Notch inhibitor & Enhance differentiation to the endocrine lineage & {$[31,32]$} & {$[19,30]$} \\
\hline & $\mathrm{H} 1152$ & ROCK inhibitor & Promote INS expression & - & {$[33]$} \\
\hline & R428 & AXL inhibitor & Promote MAFA production & - & {$[20]$} \\
\hline
\end{tabular}

$D E$ definitive endoderm; $P G$ primitive gut tube; $P P$ pancreatic progenitor; $E P$ endocrine progenitor; $E C$ endocrine cell; GSK3 $\beta$ glycogen synthase kinase 3 beta; $F G F$ fibroblast growth factor; KAAD-cyclopamine 3-keto- $N$-(aminoethylaminocaproyl-dihydrocinnamoyl) cyclopamine; $S H H$ sonic hedgehog; $K G F$ keratinocyte growth factor; $R A$ retinoic acid; BMP bone morphogenic protein; ILV Indolactom V; PDBu Phorbol 12, 13-Dibutyrate; TPB (2S,5S)-(E,E)-8-(5-(4-(trifluoromethyl)phenyl)-2,4pentadienoylamino) benzolactam; PKC protein kinase C; EGF epidermal growth factor; Alk5i transforming growth factor beta receptor inhibitor; $T 3$ thyroid hormone

loss of pancreatic gene expression, suggesting that the repression of Shh is permissive for early pancreatic development $[6,16]$. Fgf10 is expressed in the mesenchyme adjacent to the early dorsal and ventral pancreatic epithelial buds. Upon deletion of Fgf10 in mouse embryos, subsequent growth, differentiation, and branching morphogenesis of the pancreatic epithelium are arrested [14]. On the other hand, Fgf10-expressing transgenic mice exhibited cell proliferation of the pancreatic epithelium [15]. PSC-derived DE cells cultured with SHH signaling inhibitor, 3-keto- $N$-(aminoethyl-aminocaproyldihydrocinnamoyl) cyclopamine (KAAD-cyclopamine), and FGF10 resulted in PG induction [12].

Signaling pathways involving RA, PKC, BMP signaling, and others were reported to be potent in inducing PP and EP in vitro. Jiang et al. reported that the addition of all-trans retinoic acid contributed to the increased PDX1-positive cell population [10]. Exogenous addition of epidermal growth factor (EGF) was shown to increase the size of E13.5 rat pancreatic buds under 7 days of ex vivo culture [24] and was used to facilitate the expansion of the human PSC-derived PDX1-positive PPs under in vitro culture [25]. A combination of Indolactom V (ILV), a PKC agonist identified from a chemical compound screening, and FGF10 effectively increased the expressions of pancreatic lineage markers, while decreasing the expression of non-pancreatic tissue markers in three PSC lines [23]. Another PKC activator, (2S,5S)(E,E)-8-(5-(4- (Trifluoromethyl)phenyl)-2,4-pentadienoylamino) benzolactam (TPB), used with Noggin (a BMP signaling inhibitor) and Alk5 inhibitor (a TGF- $\beta$ receptor inhibitor, Alk5i), also elevated the PDX1 expression level [18]. Shahjalal et al. reported that a high dose of Noggin treatment significantly increased PDX1 expressing cells, suggesting that inhibition of BMP signaling potentiates pancreatic differentiation and suppresses hepatic and intestinal differentiation [21]. A high percentage of cells co-expressing PDX1 and another important marker for 
endocrine development $[4,6]$, NK6 homeobox 1 (NKX6.1), consequently enhances the efficiency of in vitro differentiation into EP cells. A short duration of treatment with RA, FGF10, BMP, and SHH signaling pathways inhibitors modulates the efficiency of differentiation into PPs, contributing to a higher percentage PDX1 and NKX6.1 co-expressing cells [22]. Even with the omission of BMP inhibitors, treatment with RA followed by combined treatment with EGF and keratinocyte growth factor (KGF) efficiently increased the number of both PDX1-expressing cells and subsequent PDX1/NKX6.1+ cells [26]. KGF increases beta-cell population through activation of the protein kinase $\mathrm{B} /$ Akt signaling pathway [17]. Neurogenin 3 (NEUROG3) expression defines the pancreatic EP cells, which later differentiate into ECs [34]. Continuous Noggin treatment during PP and EP stage can induce in vitro differentiation into NEUROG3-expressing cells [21]. A small molecule, sodium cromoglicate, identified from a chemical screening, was reported to facilitate differentiation into PDX1-expressing cell population derived from PSCs. Sodium cromoglicate treatment subsequently doubled the percentage of NEUROG3-positive cells compared to untreated controls [27].

During the differentiation of EP cells into ECs, various growth factors and small molecules are used to increase INSULIN-(INS)-positive EC cells. Treatment of the human fetal pancreatic islet cells with Nicotinamide (the amide form of vitamin B3) resulted in increased DNA content, thereby suggesting the expansion of the pancreatic progenitor cells, as DNA synthesis was stimulated only in the nonhormone-expressing cells [28]. Nicotinamide and FGFs were used to enhance INS-expressing EC differentiation from EP cells [10, 25]. Inhibition of the BMP signaling pathway was essential for generating INS-expressing cells [35]. Thyroid hormone (T3) and $\gamma$ secretase inhibitor XX (a Notch pathway inhibitor) are also being used to promote EC differentiation from PSCs [19]. T3 promotes pancreatic beta-cell maturation in rats [30]. In mice, misexpression of activated Notch in Pdx1expressing progenitor cells prevents differentiation into endocrine lineage [31]. In contrast, reduced Notch signaling leads to increased expression of Neurog3 that plays a key role in determining the endocrine fate [32]. From a high content chemical screen attempting to identify chemicals that facilitated INS-expression in cells, a ROCK inhibitor, H1152, was identified to increase the percentage of INS-expressing cells from PSCs [33]. Monoamine (dopamine, in particular) acts as a negative regulator that arrests the differentiation of PSCs at the PP stage. Reserpine and tetrabenazine, vesicular monoamine transporter 2 (VMAT2) inhibitors, are hit compounds identified in another high-throughput chemical screening. Adding these compounds to PSC culture decreased cellular dopamine content and potentiated late-stage differentiation into INS-expressing cells [36]. Rezania et al. focused on MAF bZIP transcription factor $A(M A F A)$, a critical beta-cell maturation marker gene [20]. They proposed that combined exposure of R428 (a small-molecule inhibitor of tyrosine kinase receptor AXL), a high dose of $\mathrm{N}$-acetyl cysteine (an antioxidant; increased antioxidants in mice beta-cells resulted in preservation of nuclear MAFA [29]), Alk5i II (TGF- $\beta$ receptor), and T3 treatment resulted in increasing MAFA transcription levels.

Among all the above growth factors and small molecules used during pancreatic differentiation, the combination, dosage, and exposure time of these components are important to obtain functional hormonal-expressing ECs. Table 2 showed a list of components used in several reports which successfully generated functional ECs using PSCs. With systematic testing of concentration and exposure time of numerous factors, Pagliuca et al. developed a protocol with the combination of various factors affecting pathways, including WNT and Activin/ Nodal (DE differentiation), SHH, EGF, TGF- $\beta$, and RA (PG, PP, and EP differentiation), T3 and $\gamma$-secretase inhibitor XX (a Notch pathway inhibitor). As a result, they successfully generated PSC-derived pancreatic islet cells that expressed not only mature beta-cell markers but were also capable of insulin packaging and improved glucose-stimulated insulin secretion [19]. With a combination of R428, a high dose of $\mathrm{N}$-acetyl cysteine, Alk5i II, and T3 treatment, Rezania et al. successfully increased the MAFA transcription levels in ECs. The pancreatic islet cells generated from PSCs expressed the key markers of mature pancreatic beta-cells, including $M A F A$. The PSC-derived pancreatic beta-cells displayed improved glucose-stimulated insulin secretion (GSIS) [20]. Velazco-Cruz et al. reported that the removal of Alk5i and T3 at the last stage of induction is crucial for generating functional beta-cells. The PSC-derived ECs exhibited increased insulin secretion and glucose responsiveness, with a dynamic first- and second-phase insulin release at a level similar to that observed in human islets [38].

Present research progress has shown that regeneration of pancreatic islets using PSCs is not an unreachable goal. There are remaining tasks in investigating the similarity and differences between PSC-derived ECs and human islets, not only with regard to the cell culture microenvironment and molecular characteristics, as well as long-term maintenance of the function of the PSCderived ECs. Recent progress regarding the cell culture microenvironment, together with transcriptome and metabolome profiles of PSC-derived ECs resulted from the differentiation procedure above, will be discussed in the later sections. 
Table 2 A list of growth factors or chemicals used for generating functional PSC-derived ECS

\begin{tabular}{|c|c|c|c|c|}
\hline \multicolumn{2}{|c|}{ References } & \multirow{2}{*}{$\begin{array}{l}\text { Pagliuca et al., } 2014 \text { [19] } \\
\text { Millman et al., } 2016 \text { [37] } \\
\text { Activin A }\end{array}$} & \multirow{2}{*}{$\begin{array}{l}\text { Rezania et al., } 2014 \text { [20] } \\
\text { GDF8 }\end{array}$} & \multirow{2}{*}{$\begin{array}{l}\text { Velazco et al., } 2019 \text { [38] } \\
\text { Activin A }\end{array}$} \\
\hline \multirow[t]{19}{*}{ Stages } & $\mathrm{DE}$ & & & \\
\hline & & CHIR99021 & GSK3 $\beta$ inh & CHIR99021 \\
\hline & PG & KGF & FGF7 & KGF \\
\hline & & & Vitamin C & LDN193189 \\
\hline & PP, EP & LDN193189 & Vitamin C & KGF \\
\hline & & KGF & RA & SANT-1 \\
\hline & & SANT-1 & SANT-1 & PDBu \\
\hline & & PDBu & TPB & RA \\
\hline & & RA & LDN & Y27632 \\
\hline & & Y27632 & Alk5 inh & Activin A \\
\hline & & Activin A & T3 & \\
\hline & & & LDN193189 & \\
\hline & EC & SANT-1 & Alk5 inh & SANT-1 \\
\hline & & RA & T3 & RA \\
\hline & & GSXX inh & LDN & GSXX inh \\
\hline & & Alk5 inh & GSXX inh & Alk5 inh \\
\hline & & T3 & NAC & T3 \\
\hline & & Betacellulin & AXL inh & Betacellulin \\
\hline & & Heparin & & \\
\hline
\end{tabular}

\section{Cell culture microenvironment in differentiating PSCs}

Apart from the optimization of medium components, several studies highlighted that cell culture system, such as adherent culture, culture in suspension, or reaggregation culture, during differentiation could affect pancreatic differentiation. Directed differentiation was initially done using adherent culture systems. In an attempt to overcome surface-area constraints, achieve manufacturingscale culture, and prepare enough cells for transplantation, suspension procedures were proposed [39, 40]. Further experiments showed that cell aggregation promoted the generation of PDX1/NKX6.1-positive cell populations derived from PSCs [41]. Controlling the size of the cell clusters at the final stage of differentiation [38] or isolating and reaggregating ECs into islet-sized clusters [42] resulted in cells of higher quality that exhibited dynamic insulin secretion. Results on the single-cell analysis of PPs derived from PSCs revealed that cell confinement is a prerequisite for endocrine specification [43], emphasizing the necessity of cell clustering in islet formation. Late-stage differentiation has also been performed in an air-liquid interface culture environment, mimicking an environment that may modulate beta-cell differentiation [20].

The state of the cytoskeleton was reported to affect the expression levels of transcription factors for endocrine differentiation. PSCs cultured under adherent conditions were reported to yield a decreased differentiation efficiency into ECs. This issue was overcome by treatment with a cytoskeletal depolymerizer latrunculin A. Under adherent cultures of three PSC cell lines, latrunculin A treatment yielded islet cells exhibiting key markers of mature pancreatic cells and dynamic insulin secretion with first- and second-phase [44]. A detailed map of endocrine differentiation was constructed using a single-cell transcriptome of the developing mouse pancreatic islets. These results showed that islet formation does not involve migration and aggregation of multiple individual cells. Instead, the islets form as budding peninsulas, or more commonly known as endocrine budding. Early differentiating alpha-cells appear at the tip of the peninsula, and the later differentiating beta-cells form in the rear. Under suspension culture conditions and optimized pancreatic differentiation procedures of the PSCs, bud-like protrusions appeared from the bulk of the spheroids (cell clusters of beta-like cells). Flow cytometry analysis revealed that the cells in the buds expressed a higher percentage of Chromogranin A (CHGA), INS, and Glucagon (GCG) compared to the cells in the bulks. The results suggest that PSCs can be induced in vitro to generate hormone-secreting cells within a peninsula-like structure similar to that observed during developmental processes in the mouse [45]. Overall, studying the connection between cell culture 
microenvironment and endocrine differentiation might lead to a more efficient regeneration of pancreatic islets in vitro.

\section{Single-cell RNA sequencing revealed heterogeneous cell population and lineage bifurcations in PSC-derived ECs}

Given that significant progress has been made in directed differentiation of pancreatic islet cells from PSCs, recent investigations utilized transcriptome sequencing and metabolome analysis of the differentiating PSCs to characterize their cellular identity. Compared to the bulk RNA sequencing result of PSC-derived INS-expressing cells before aggregation, reaggregated PSC-derived INSexpressing cell clusters showed a higher degree of correlation with beta-cells isolated from adult human islets [42]. From single-cell RNA sequencing (scRNA-seq) analysis, Veres et al. reported a heterogeneous cell population in PSC-derived islet cells, showing four major cell populations. They are (1) beta-cells that express INS, NKX6.1, and other beta-cell markers; (2) polyhormonal alpha-like cells that express GCG, Aristaless-related homeobox $(A R X)$, and INS; (3) enterochromaffin cells and endocrine cell types expressing $C H G A$, Tryptophan hydroxylase 1 (TPH1), LIM homeobox transcription factor 1 alpha $(L M X 1 A)$, and Solute carrier family $18 \mathrm{mem}$ ber A1 (SLC18A1); and (4) SRY-Box Transcription Factor 9-(SOX9)-expressing non-ECs (a pancreatic duct marker of exocrine cells). A surface marker of PSCderived beta-cells, CD49 antigen-like family member A (CD49a), was identified, and pure PSC-derived beta-cell clusters were generated [46]. In vitro directed differentiation into pancreatic islet cells was performed in a stepwise manner as shown in Fig. 1a. Petersen et al. and Sharon et al. showed lineage bifurcations or two waves of endocrine differentiation after the PP stage, analyzed by scRNA-seq of PSC-derived ECs. Petersen et al. found lineage convergence among the EP cells, focusing on the expression of motor neuron and pancreas homeobox $(M N X)$. $M N X$-positive cells will eventually express NKX6.1 and E-twenty-six (ETS) transcription factor, Fifth Ewing variant (FEV). FEV expression precedes LIM homeobox 1 (ISL1) in EP cells that mark cells on the beta-cell pathway. $M N X$-negative cells in turn give rise to the FEV-negative ISL1-positive cell population which further progress into $A R X$ - and INS-positive cells, attesting to the polyhormonal characteristics of the cells [47]. Sharon et al. reported that homogeneous differentiation only occurs in the first three stages (DE, PG, and PP). From EP onwards, the clusters contained heterogeneous populations, including epithelial-cord markers and endocrine markers-expressing cells (endocrine precursors, alpha-cell markers-, beta-cell markers-expressing cells, and enteroendocrine cells) (Fig. 1b). There were two waves of endocrine differentiation, in which alpha-cells started to form in the first wave. The second wave gives rise to beta-cells and non-pancreatic ECs. Also, they reported that WNT inhibition plays a role in endocrine differentiation. Treatment of WNT-tankyrase inhibitor, IWR1-endo increased the percentage of the endocrine marker, CHGA, and PP markers, PDX1/NKX6.1-positive cell populations [48].

In a recent report, Helman et al. performed a metabolic analysis of PSC-derived beta-cells, focusing specifically on their glucose responsiveness. The authors investigated the possibility that sensing environmental nutrients by mechanistic target of rapamycin complex 1 (mTORC1) contributes to islet cell maturation. They found that the mTORC1 pathway was strongly activated in fetal beta-cells, while adult human beta-cells showed low mTORC1 activity. The activated mTORC1 was responsive to glucose and amino acids. By culturing PSCderived beta-cells under an amino acid-rich, but not glucose-rich medium, activation of the mTORC1 signaling pathway was observed, evidencing their similarity with fetal beta-cells. Inhibition of the mTORC1 signaling with an mTOR inhibitor, Torin1, improved glucoseresponsive insulin secretion of PSC-derived beta-cells [49]. The finding suggests a transition of nutrientsensitivity in the mTORC1 pathway triggers glucoseresponsive insulin secretion. Utilizing this $\mathrm{mTORC} 1 \mathrm{sig}$ naling pathway led to the improvement in generating functional insulin secreting-beta-cells derived from PSCs. Davis et al. investigated glucose metabolism and sensing in PSC-derived beta-cells and found that a bottleneck in glycolysis inhibits glucose response. They reported that the glucose sensing and regulation of insulin secretion had not achieved the level of those observed with human islets in vitro. During glucose challenges, glucose-induced anaplerotic flux was observed in the human islets through pyruvate carboxylase (a mitochondrial enzyme that catalyzes the carboxylation of pyruvate to oxaloacetate during glycogenesis). However, this was not observed in PSC-derived beta-cells, thereby suggesting a deficiency exists in the glycolytic pathway. They further showed that the application of metabolites from late glycolysis could rescue the PSC-derived beta-cells to acquire insulin secretion activity [50].

Functional islets derived from PSCs can be analyzed using scRNA-seq to determine novel signaling pathways and lineage commitment of PSCs during pancreatic differentiation and maturation. At the same time, metabolome studies enable us to acquire information on PSC-derived islet cell function. These approaches will provide us a clearer picture to understand the specific molecules involved and the exact timing for differentiation cues, facilitating the future development of directed differentiation to generate functional pancreatic islets from the PSCs. 
Transplantation of pancreatic islet cells derived from PSCs As islet transplantation progressed over the past decades, these following aspects are reported to be ideal for transplant procedures: ready access to oxygen, glucose and insulin delivery, minimal procedural risk, longterm functionality and low inflammatory reaction, and monitoring of islet after transplantation. To reduce substantial islet cell loss and graft inflammation, alternative transplantation sites, cell sources, and encapsulation technologies were studied to improve islet transplantation $[51,52]$.

PSC-derived pancreatic beta-cells generated in vitro via directed differentiation mentioned above, as an alternative cell source, were transplanted into the immunocompromised diabetic mouse models to verify their function under in vivo environment $[19,20]$. Immunocompromised mice, such as SCID-Beige, NOD SCID, or NSG mice, treated with streptozotocin (STZ) to induce diabetes, or immunodeficient NRG-Akita diabetic mice were used. Pagliuca et al. reported that fasting blood glucose levels after PSC-derived pancreatic cell transplantation reversed to normal glycemia, compared to progressively increased blood glucose levels in the control mice [19]. Rezania et al. reported a decrease in fasting blood glucose levels after two weeks of transplantation into STZ-diabetic mice. However, it was after
40 days post-transplantation that blood glucose levels significantly reduced beyond pre-STZ levels. Hyperglycemia was observed after graft removal, showing a lack of insulin secretion in the circulation post-nephrectomy [20].

The functionality of the engrafted PSC-derived pancreatic islet cells can be confirmed on the condition that transplanted cells exhibited a high population of INS- or other mature beta-cell marker-expressing cells [19, 20, $38,42,44]$. Further efforts are expected to establish the delivery system of PSC-derived islet cells. In 2018, Gamble et al. had reviewed a novel approach to graft implantation: the use of islet encapsulation devices [51]. Macro- and microencapsulation devices that allow penetration of oxygen and nutrients, hormone flow, and protect inner cells from humoral and cell-mediated immunity are preferable (Fig. 2). ViaCyte, Inc. (San Diego, California) developed a planar macro encapsulation device that can be loaded with functional pancreatic progenitors derived from PSCs (PEC-01) and implanted subcutaneously. The implanted cell/device combination product, VC-01, underwent Phase I/II clinical trials in 2014 (NCT02239354). ViaCyte launched a second trial (NCT03163511) using the PEC-01 cells encapsulated in a novel device, VC-02, in 2017. The novel device allows neovascularization that might improve the survival of

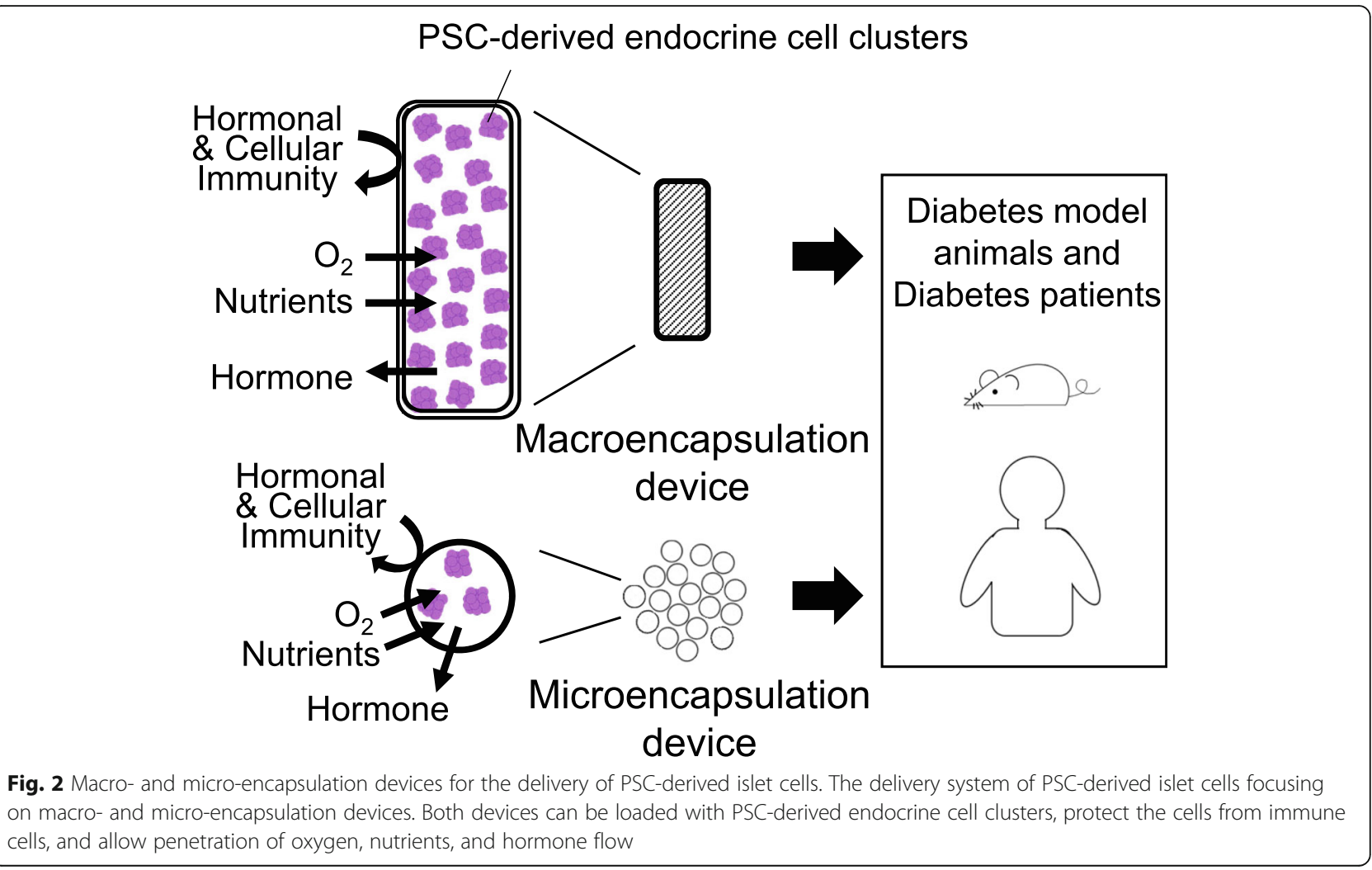


the encapsulated cells but would require long-term immunosuppression. On the other hand, microencapsulation devices are made up of polymer-based biomaterial that encapsulates individual islet or islet clusters. Longterm glycemic correction of more than 100 days was achieved in diabetic mice engrafted with PSC-derived pancreatic islet cells encapsulated with chemically modified alginate [53]. Follow-up studies are yet to be done on investigating the efficiency and safety of long-term implantation as well as the cost for cell therapy.

\section{Combining gene-editing technology and directed differentiation open a new avenue to disease modeling and drug testing}

PSC technology is opening the door to study specific disease mechanisms and therapies via disease modeling and drug testing as the generation of PSCs using somatic cells from patients has become possible [54]. There are successful cases of PSCs generated from somatic cells and fibroblasts of diabetic patients [55, 56]. Pancreatic islet cells generated from PSCs of type 1 diabetic patients expressed mature beta-cell markers, and responded to glucose challenge, did not show major differences with non-diabetic patients [37, 57]. Fibroblast cells from patients with single mutation-caused diabetes, maturity-onset diabetes of the young (MODY) can be reprogrammed into PSCs, expressing pluripotency markers and the ability to differentiate into cells derived from three germ layers $[58,59]$. PSCs derived from MODY patients were differentiated into pancreatic cells, however, did not have significant changes in immunostaining for PDX1 and gene expression for pancreatic differentiation markers, such as NKX6.1 and INS compared to control individual [60,61].

Recent progress was made through optimization of the differentiation procedures and application of geneediting technology, the CRISPR-Cas9 system, using PSCs from diabetic patients. Unlike type 1 diabetic patients, these patients carry specific gene mutations that cause diabetes [62, 63]. Balboa et al. generated PSCs from patients carrying INS mutations, used CRISPR-Cas9 to engineer mutation-corrected lines, and differentiated them to beta-like cells. Comparing the INS mutant and corrected beta-like cells, the mutant-derived beta-cells showed increased endoplasmic reticulum (ER) stress and reduced cell proliferation [62]. From the corrected PSCs derived from permanent neonatal diabetes mellitus (PNDM) patients, insulin-secreting pancreatic islet cells were generated, and upon transplantation into mice protected the mice from diabetes [64]. Maxwell et al. corrected a diabetes-causing pathogenic variant in Wolfram syndrome 1 in PSCs derived from a Wolfram syndrome patient using CRISPR-Cas9. By applying the adhesion culture system reported from the same group [44], unedited and corrected PSCs were differentiated into CPEPTIDE (a by-product of INS formation)-positive betacells, co-expressing NKX6.1 and PDX1. C-PEPTIDE/ NKX6.1-positive cell population was lower in the unedited compared to the corrected PSC-derived betacells. The gene-edited PSC-derived beta-cells displayed increased insulin secretion and higher glucoseresponsiveness compared to controls. Upon transplantation, the cells successfully normalized blood glucose and reversed pre-existing diabetes in mice [63]. The
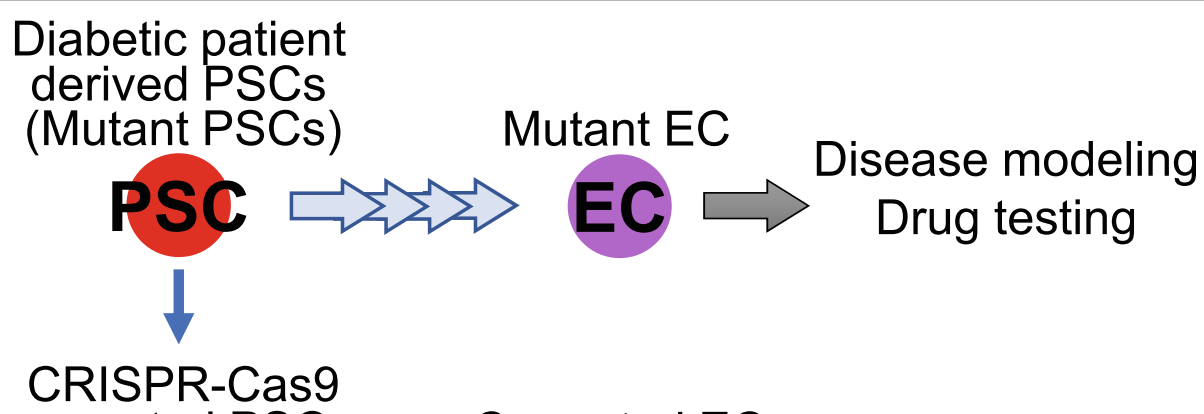

corrected PSCs Corrected EC
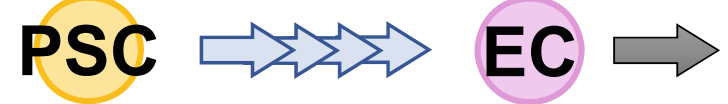

Autologous cell therapy

\section{Gene-editing + Directed differentiation}

Fig. 3 Combining gene-editing and directed differentiation for the development of novel therapeutics. Patient-derived endocrine cells can be applied in disease modeling and drug testing, while corrected PSC-derived endocrine cells can be a promising source for autologous cell therapy 
result shows that directed differentiation and gene editing can be combined in the study of disease modeling, suggesting promising results for autologous cell therapy (Fig. 3). Drug testing and pathological studies of diabetes using islet cells derived from the patient's PSCs are expected to be useful for the development of therapeutic drugs.

\section{Conclusions}

Generation of functional pancreatic islet cells using PSCs had become possible based on the substantial progress made over the past years. Also, transplanted PSCderived islet cells have shown the ability to normalize pre-existing hyperglycemia in mice. Follow-up research in the next decade would likely be focused more on molecular mechanisms of PSC-derived islet cells, delivery systems for transplantation, and experimental disease treatment involving the application of patient PSCderived islet cells for therapeutic efficacy and safety considerations.

\section{Abbreviations}

ARX: Aristaless-related homeobox; BMP: Bone morphogenic protein; CHGA: Chromogranin A; DE: Definitive endoderm; EC: Endocrine cell; EGF: Epidermal growth factor; EP: Endocrine progenitor; FEV: Fifth Ewing Variant; FGF: Fibroblast growth factor; GCG: Glucagon; INS: Insulin; ISL1: ISL LIM homeobox 1; MAFA: MAF bZIP transcription factor A; MNX: Motor neuron and pancreas homeobox; mTORC1: Mechanistic target of rapamycin complex 1; NEUROG3: Neurogenin 3; NKX6.1: NK6 homeobox 1; PDX1: Pancreatic and duodenal homeobox 1; PG: Primitive gut tube; PKC: Protein kinase C; PP: Pancreatic progenitor; PSCs: Pluripotent stem cells; RA: Retinoic acid; scRNA-seq: Single-cell RNA sequencing; SHH: Sonic Hedgehog; TGF- $\beta$ : Transforming growth factor- $\beta$; VMAT2: Vesicular monoamine transporter 2

\section{Acknowledgements}

We thank Ms Sylvia Leo for critical reading of the manuscript.

\section{Authors' contributions}

ES contributes to the writing, discussion, and revision of the manuscript; NS contributes to the discussion; SK contributes to the discussion, writing, revision, and approval of the final version of the manuscript. The authors read and approved the final manuscript.

\section{Funding}

This work was supported by Grants-in-Aid from the Ministry of Education, Culture, Sports, Science and Technology (MEXT) Japan (\#18H02861 to SK, \#18H02154 to NS), by the Takeda Science Foundation (to SK), and the Japanese Insulin Dependent Diabetes Mellitus (IDDM) Network Foundation.

\section{Availability of data and materials}

Not applicable

\section{Ethics approval and consent to participate}

Not applicable

\section{Consent for publication}

All authors agree with the content and the publication of this article.

\section{Competing interests}

The authors declare no conflict of interest.
Received: 14 July 2020 Accepted: 15 December 2020

Published online: 05 January 2021

\section{References}

1. Corrêa-giannella ML, Raposo AS. Pancreatic islet transplantation. Diabetol Metab Syndr. 2009;1:1-7.

2. Thomson JA, Itskovitz-eldor J, Shapiro SS, Waknitz MA, Swiergiel JJ, Marshall VS, et al. Embryonic stem cell lines derived from human blastocysts. Science. 1998;282:1145-7.

3. Takahashi K, Tanabe K, Ohnuki M, Narita M, Ichisaka T, Tomoda K. Induction of pluripotent stem cells from adult human fibroblasts by defined factors. Cell. 2007;131:861-72.

4. Gittes GK. Developmental biology of the pancreas: a comprehensive review. Dev Biol. 2009;326:4-35. https://doi.org/10.1016/j.ydbio.2008.10.024.

5. Murtaugh LC. Pancreas and beta-cell development: from the actual to the possible. Development. 2007;134:427-38.

6. Wells JM, Melton D. Vertebrate endoderm development. Annu Rev Cell Dev Biol. 1999:15:393-410.

7. Vincent SD, Dunn NR, Hayashi S, Norris DP, Robertson EJ. Cell fate decisions within the mouse organizer are governed by graded nodal signals. Genes Dev. 2003;17:1646-62. https://doi.org/10.1101/gad.1100503.gion.

8. de Caestecker $M$. The transforming growth factor- $\beta$ superfamily of receptors. Cytokine Growth Factor Rev. 2004;15:1-11.

9. D'Amour KA, Agulnick AD, Eliazer S, Kelly OG, Kroon E, Baetge EE. Efficient differentiation of human embryonic stem cells to definitive endoderm. Nat Biotechnol. 2005;23:1534-41. https://doi.org/10.1038/nbt1163.

10. Jiang W, Shi Y, Zhao D, Chen S, Yong J, Zhang J, et al. In vitro derivation of functional insulin-producing cells from human embryonic stem cells. Cell Res. 2007;17:333-44. https://doi.org/10.1038/cr.2007.28.

11. Liu P, Wakamiya M, Shea MJ, Albrecht U, Behringer RR, Bradley A. Requirement for Wnt3 in vertebrate axis formation. Nat Genet. 1999;22:361-5.

12. D'Amour KA, Bang AG, Eliazer S, Kelly OG, Agulnick AD, Smart NG, et al. Production of pancreatic hormone-expressing endocrine cells from human embryonic stem cells. Nat Biotechnol. 2006;24:1392-401. https://doi.org/10. 1038/nbt1259.

13. Kunisada Y, Tsubooka-Yamazoe N, Shoji M, Hosoya M. Small molecules induce efficient differentiation into insulin-producing cells from human induced pluripotent stem cells. Stem Cell Res. 2012;8:274-84. https://doi. org/10.1016/j.scr.2011.10.002

14. Bhushan A, Itoh N, Kato S, Thiery JP, Czernichow P, Bellusci S, et al. Fgf10 is essential for maintaining the proliferative capacity of epithelial progenitor cells during early pancreatic organogenesis. Development. 2001;128:5109-17.

15. Hart A, Papadopoulou S, Edlund H. Fgf10 maintains notch activation, stimulates proliferation, and blocks differentiation of pancreatic epithelial cells. Dev Dyn. 2003;228:185-93.

16. Hebrok M, Kim SK, Melton DA. Notochord repression of endodermal sonic hedgehog permits pancreas development. Genes Dev. 1998;12:1705-13.

17. Wagner M, Koschnick S, Beilke S, Frey M, Adler G, Schmid RM. Selective expansion of the $\beta$-cell compartment in the pancreas of keratinocyte growth factor transgenic mice. Am J Physiol Gastrointest Liver Physiol. 2008; 294:1139-47.

18. Rezania A, Bruin JE, Riedel MJ, Mojibian M, Asadi A, Xu J, et al. Maturation of human embryonic stem cell-derived pancreatic progenitors into functional islets capable of treating pre-existing diabetes in mice. Diabetes. 2012;61: 2016-29. https://doi.org/10.2337/db11-1711.

19. Pagiluca FW, Millman JR, Gurtler M, Segel M, Van Dervort A, Ryu JH, et al. Generation of functional human pancreatic B cells in vitro. Cell. 2014;159: 428-39. https://doi.org/10.1530/ERC-14-0411.Persistent.

20. Rezania A, Bruin JE, Arora P, Rubin A, Batushansky I, Asadi A, et al. Reversal of diabetes with insulin-producing cells derived in vitro from human pluripotent stem cells. Nat Biotechnol. 2014;32:1121-33.

21. Shahjalal HM, Shiraki N, Sakano D, Kikawa K, Ogaki S, Baba H, et al. Generation of insulin-producing $\beta$-like cells from human iPS cells in a defined and completely xeno-free culture system. J Mol Cell Biol. 2014;6: 394-408. https://doi.org/10.1093/jmcb/mju029.

22. Nostro MC, Sarangi F, Yang C, Holland A, Elefanty AG, Stanley EG, et al. Efficient generation of NKX6-1+ pancreatic progenitors from multiple human pluripotent stem cell lines. Stem Cell Reports. 2015;4:591-604. https://doi.org/10.1016/j.stemcr.2015.02.017. 
23. Chen S, Borowiak M, Fox JL, Maehr R, Osafune K, Davidow L, et al. A small molecule that directs differentiation of human ESCs into the pancreatic lineage. Nat Chem Biol. 2009;5:258-65. https://doi.org/10.1038/nchembio.154.

24. Cras-Méneur C, Elghazi L, Czernichow P, Scharfmann R. Epidermal growth factor increases undifferentiated pancreatic embryonic cells in vitro: a balance between proliferation and differentiation. Diabetes. 2001;50:1571-9.

25. Zhang D, Jiang W, Liu M, Sui X, Yin X, Chen S, et al. Highly efficient differentiation of human ES cells and iPS cells into mature pancreatic insulinproducing cells. Cell Res. 2009;19:429-38. https:/doi.org/10.1038/cr.2009.28.

26. Russ HA, Parent AV, Ringler JJ, Hennings TG, Nair GG, Shveygert M, et al. Controlled induction of human pancreatic progenitors produces functional beta-like cells in vitro. EMBO J. 2015;34:1759-72. https://doi.org/10.15252/ embj.201591058

27. Kondo $Y$, Toyoda $T$, Ito R, Funato M, Hosokawa $Y$, Matsui $S$, et al. Identification of a small molecule that facilitates the differentiation of human iPSCS/ESCs and mouse embryonic pancreatic explants into pancreatic endocrine cells. Diabetologia. 2017;60:1454-66.

28. Otonkoski T, Beattie GM, Mally MI, Ricordi C, Hayek A. Nicotinamide is a potent inducer of endocrine differentiation in cultured human fetal pancreatic cells. J Clin Invest. 1993;92:1459-66.

29. Harmon JS, Bogdani M, Parazzoli SD, Mak SSM, Oseid EA, Berghmans M, et al. $\beta$-cell-specific overexpression of glutathione peroxidase preserves intranuclear MafA and reverses diabetes in db/db Mice. Endocrinology. 2009;150:4855-62.

30. Aguayo-Mazzucato C, Zavacki AM, Marinelarena A, Hollister-Lock J, El Khattabi I, Marsili A, et al. Thyroid hormone promotes postnatal rat pancreatic $\beta$-cell development and glucose-responsive insulin secretion through MAFA. Diabetes. 2013;62:1569-80.

31. Murtaugh LC, Stanger BZ, Kwan KM, Melton DA. Notch signaling controls multiple steps of pancreatic differentiation. Proc Natl Acad Sci U S A. 2003;100: 14920-5.

32. Apelqvist $\AA$, Li H, Sommer L, Beatus P, Anderson DJ, Honjo T, et al. Notch signalling controls pancreatic cell differentiation. Nature. 1999;400:877-81.

33. Ghazizadeh Z, Kao D-I, Amin S, Cook B, Rao S, Zhou T, et al. ROCKII inhibition promotes the maturation of human pancreatic beta-like cells. Nat Commun. 2017;8:1-12. https://doi.org/10.1038/s41467-017-00129-y.

34. Gu G, Dubauskaite J, Melton DA. Direct evidence for the pancreatic lineage: $\mathrm{NGN3}+$ cells are islet progenitors and are distinct from duct progenitors. Development. 2002;129:2447-57.

35. Nostro MC, Sarangi F, Ogawa S, Holtzinger A, Corneo B, Li X, et al. Stagespecific signaling through TGF family members and WNT regulates patterning and pancreatic specification of human pluripotent stem cells. Development. 2011;138:861-971. https://doi.org/10.1242/dev.065904.

36. Sakano D, Shiraki N, Kikawa K, Yamazoe T, Kataoka M, Umeda K, et al. VMAT2 identified as a regulator of late-stage $\beta$-cell differentiation. Nat Chem Biol. 2014;10:141-8. https://doi.org/10.1038/nchembio.1410.

37. Rajaei B, Shamsara M, Amirabad LM, Massumi M, Sanati MH. Pancreatic endoderm-derived from diabetic patient-specific induced pluripotent stem cell generates glucose-responsive insulin-secreting cells. J Cell Physiol. 2017; 232:2616-25.

38. Velazco-Cruz L, Song J, Maxwell KG, Goedegebuure MM, Augsornworawat P, Hogrebe $\mathrm{NJ}$, et al. Acquisition of dynamic function in human stem cellderived $\beta$ cells. Stem Cell Reports. 2019;12:351-65. https://doi.org/10.1016/j. stemcr.2018.12.012.

39. Schulz TC, Young HY, Agulnick AD, Babin MJ, Baetge EE, Bang AG, et al. A scalable system for production of functional pancreatic progenitors from human embryonic stem cells. PLoS One. 2012;7:e37004. https://doi.org/10. 1371/journal.pone.0037004

40. Yabe SG, Fukuda S, Nishida J, Takeda F, Nashiro K, Okochi H. Induction of functional islet-like cells from human iPS cells by suspension culture. Regen Ther. 2019;10:69-76. https://doi.org/10.1016/j.reth.2018.11.003.

41. Toyoda T, Mae SI, Tanaka H, Kondo Y, Funato M, Hosokawa Y, et al. Cell aggregation optimizes the differentiation of human ESCs and iPSCs into pancreatic bud-like progenitor cells. Stem Cell Res. 2015;14:185-97. https:// doi.org/10.1016/j.scr.2015.01.007.

42. Nair GG, Liu JS, Russ HA, Tran S, Saxton MS, Chen R, et al. Recapitulating endocrine cell clustering in culture promotes maturation of human stemcell-derived $\beta$ cells. Nat Cell Biol. 2019;21:263-74. https://doi.org/10.1038/ s41556-018-0271-4.

43. Mamidi A, Prawiro C, Seymour PA, de Lichtenberg KH, Jackson A, Serup P, et al. Mechanosignalling via integrins directs fate decisions of pancreatic progenitors. Nature. 2018;564:114-8. https://doi.org/10.1038/s41586-018-0762-2.
44. Hogrebe NJ, Augsornworawat P, Maxwell KG, Velazco-Cruz L, Millman JR. Targeting the cytoskeleton to direct pancreatic differentiation of human pluripotent stem cells. Nat Biotechnol. 2020;38:460-70.

45. Sharon N, Chawla R, Mueller J, Vanderhooft J, Whitehorn JL, Rosenthal B, et al. A peninsular structure coordinates asynchronous differentiation with morphogenesis to generate pancreatic islets. Cell. 2019;176:790-804.

46. Veres A, Faust AL, Bushnell HL, Engquist EN, Kenty JHR, Harb G, et al. Charting cellular identity during human in vitro $\beta$-cell differentiation. Nature 2019:569:368-73. https://doi.org/10.1038/s41586-019-1168-5.

47. Petersen MBK, Azad A, Ingvorsen C, Hess K, Hansson M, Grapin-Botton A, et al. Single-cell gene expression analysis of a human esc model of pancreatic endocrine development reveals different paths to $\beta$-cell differentiation. Stem Cell Reports. 2017;9:1246-61.

48. Sharon N, Vanderhooft J, Straubhaar J, Mueller J, Chawla R, Zhou Q, et al. Wnt signaling separates the progenitor and endocrine compartments during pancreas development. Cell Rep. 2019;27:2281-91. https://doi.org/10. 1016/j.celrep.2019.04.083.

49. Helman A, Cangelosi AL, Davis JC, Pham Q, Rothman A, Faust AL, et al. A nutrient-sensing transition at birth triggers glucose-responsive insulin secretion. Cell Metab. 2020;31:1004-16. https://doi.org/10.1016/j.cmet.2020.04.004.

50. Davis JC, Alves TC, Helman A, Chen JC, Kenty JH, Cardone RL, et al. Glucose response by stem cell-derived $\beta$ cells in vitro is inhibited by a bottleneck in glycolysis. Cell Rep. 2020;31:107623. https://doi.org/10.1016/j.celrep.2020.107623.

51. Gamble A, Pepper AR, Bruni A, Shapiro AMJ. The journey of islet cell transplantation and future development. Islets. 2018;10:80-94. https://doi. org/10.1080/19382014.2018.1428511.

52. Shapiro AMJ, Pokrywczynska M, Ricordi C. Clinical pancreatic islet transplantation. Nat Rev Endocrinol. 2017;13:268-77. https://doi.org/10.1038/ nrendo.2016.178.

53. Vegas AJ, Veiseh O, Gürtler M, Millman JR, Pagliuca FW, Bader AR, et al. Long-term glycemic control using polymer-encapsulated human stem cellderived beta cells in immune-competent mice. Nat Med. 2016;22:306-11.

54. Inoue H, Nagata N, Kurokawa H, Yamanaka S. iPS cells: a game changer for future medicine. EMBO J. 2014;33:409-17. https://doi.org/10.1002/embj. 201387098.

55. Park $I H$, Arora N, Huo H, Maherali N, Ahfeldt T, Shimamura A, et al. Diseasespecific induced pluripotent stem cells. Cell. 2008;134:877-86.

56. Jang J, Yoo JE, Lee JA, Lee DR, Kim JY, Huh YJ, et al. Disease-specific induced pluripotent stem cells: a platform for human disease modeling and drug discovery. Exp Mol Med. 2012;44:202-13.

57. Millman JR, Xie C, Van Dervort A, Gürtler M, Pagliuca FW, Melton DA. Generation of stem cell-derived $\beta$-cells from patients with type 1 diabetes. Nat Commun. 2016;7:11463. https://doi.org/10.1038/ncomms11463.

58. Teo AKK, Windmueller R, Johansson BB, Dirice E, Njolstad PR, Tjora E, et al. Derivation of human induced pluripotent stem cells from patients with maturity onset diabetes of the young. J Biol Chem. 2013;288:5353-6.

59. Yabe SG, Iwasaki N, Yasuda K, Hamazaki TS, Konno M, Fukuda S, et al. Establishment of maturity-onset diabetes of the young-induced pluripotent stem cells from a Japanese patient. J Diabetes Investig. 2015;6:543-7.

60. Stepniewski J, Kachamakova-Trojanowska N, Ogrocki D, Szopa M, Matlok M, Beilharz $M$, et al. Induced pluripotent stem cells as a model for diabetes investigation. Sci Rep. 2015:5:1-14.

61. Braverman-Gross C, Nudel N, Ronen D, Beer NL, McCarty MI, Benvenisty N. Derivation and molecular characterization of pancreatic differentiated MODY1-iPSCs. Stem Cell Res. 2017;2018(31):16-26. https://doi.org/10.1016/j. scr.2018.06.013.

62. Balboa D, Saarimäki-Vire J, Borshagovski D, Survila M, Lindholm P, Galli E, et al. Insulin mutations impair beta-cell development in a patient-derived iPSC model of neonatal diabetes. Elife. 2018;7:1-35.

63. Maxwell KG, Augsornworawat P, Velazco-cruz L, Kim MH, Asada R, Hogrebe $\mathrm{NJ}$, et al. Gene-edited human stem cell - derived beta cells from a patient with monogenic diabetes reverse preexisting diabetes in mice. Sci Transl Med. 2020;12:eaax9106.

64. Ma S, Viola R, Sui L, Cherubini V, Barbetti F, Egli D. Beta cell replacement after gene editing of a neonatal diabetes-causing mutation at the insulin locus. Stem Cell Rep. 2018:11:1407-15.

\section{Publisher's Note}

Springer Nature remains neutral with regard to jurisdictional claims in published maps and institutional affiliations. 